\title{
Guideline zum Vorgehen bei suspektem und positivem zytologischem Abstrich der Cervix uteri
}

\author{
Überarbeitete Fassung, Version 2.4
}

Arbeitsgruppe «Guideline Zervixabstrich» *

\footnotetext{
Kommission Qualitätssicherung (Präsident Prof. Dr. U. Haller, Zürich) der Schweizerischen Gesellschaft für Geburtshilfe und Gynäkologie (SGGG)

Leiter der Expertengruppe und Koordinator: Prof. Dr. S. Heinzl, SGGG, Bruderholz / Basel

Mitglieder: Prof. Dr. A. Almendral, SGGG, Basel; PD Dr. M. Fehr, SGGG, Zürich; Prof. Dr. Dr. h.c. G. Feichter, SGZ, Basel; Dr. J. Obwegeser, exec. MBA (HSG), SGGG, SGZ, Zürich; Prof. Dr. P. Sauthier, SGGG, Lausanne / Montréal; Dr. G. Szalmay, SGGG, St. Gallen; PD Dr. E. Wight, SGGG, Basel.
}

\section{Präambel}

Im weiten Bereich der Qualitätssicherung im Gesundheitswesen stellen Guidelines ein wichtiges und sinnvolles Segment dar, welches der Ärztin und dem Arzt in komplexen und sich rasch verändernden Fragestellungen in Diagnose, Therapie und medizinischer Technik eine wertvolle Hilfeleistung bietet. Guidelines sollen sich auf evidenzbasierte Publikationen und Expertenmeinungen abstützen und stellen damit den aktuellen Stand des Wissens dar. Sie gelten für den Regelfall; sie sind somit keine in jedem Einzelfall gültigen Handlungsanweisungen und damit auch keine Untersuchungs- und Behandlungsalgorithmen. Sie lassen der Ärztin und dem Arzt die Entscheidung offen, allenfalls von ihnen abzuweichen. Die individuelle Situation der Patientin, des Patienten - insbesondere bei Polymorbidität - ist zu berücksichtigen und zwingt unter Umständen dazu, von den Vorgaben einer Guideline abzuweichen. Ein solches Vorgehen kann und sollte begründet werden. Sofern eine Guideline gewisse qualitative Kriterien und Anforderungen erfüllt, ist sie ein geeignetes Mittel, den medizinischen Entscheidungsprozess zu erleichtern und damit auch die Qualität der ärztlichen Versorgung zu verbessern, auch wenn es äusserst schwierig ist, das Resultat der Anwendung einer Guideline zu evaluieren.

Die Erarbeitung einer Guideline erfordert Zeit, Geduld und viel Engagement einer Expertengruppe. Ist die Guideline nach den Prinzipien der Evidence-based Medicine und eines Expertenkonsensus erstellt, so müsste sie eigentlich weltweit immer identisch sein. Gesundheitssysteme, Ausbildung der Ärztinnen und Ärzte, Behandlungstraditionen, ethische und religiöse sowie epidemiologische Unterschiede können jedoch eine Guideline beeinflussen, so dass sie nicht telquel von einem anderen Land übernommen werden kann.

\section{Einleitung}

\subsection{Relevanz des Themas}

Das Zervixkarzinom ist das häufigste Genitalkarzinom weltweit. Allerdings verzeichnen die industrialisierten Länder dank der primären und sekundären Prävention eine geringere Häufigkeit. Ein deutlicher Rückgang zeigte sich vor allem in Europa im Verlaufe der letzten 40 Jahre. Einen nicht unwesentlichen Anteil haben dabei die Vorsorgeuntersuchungen, insbesondere der zytologische Abstrich nach Papanicolaou [13, $17,32,38,44,45,55,63,71,72,79,87,88,97$, 103, 113, 119, 126]. Mit dem Zervixabstrich sollen in erster Linie Vorstadien des Zervixkarzinoms entdeckt werden.

Die gute Zugänglichkeit der Zervix ermöglicht es, bereits Vorstufen und Frühformen zu erkennen. Dazu gibt es zwei etablierte, sich ergänzende Methoden: die Zytologie und die Kolposkopie. Beide Methoden haben ihre Vorund Nachteile, wobei sich die Zytologie als Screening-Methode vor allem in den angelsächsischen Ländern besser durchgesetzt hat. Idealerweise werden beide Methoden miteinander kombiniert [19, 32, 39, 69, 103, 119]. Muss man sich aus Kostengründen auf eine Methode beschränken, ist die Zytologie zu favorisieren [13, 20, 24, 34, 71, 115].

Die Qualität und die Quantität der zytologisch erfassten Zellveränderungen erlauben es, Rückschlüsse auf den Schweregrad der Läsion zu ziehen. Die Methode ist mit falschen Resultaten behaftet. Man rechnet mit bis zu 40\% falsch negativen und mit 1-5\% falsch positiven Befunden. Die Qualität des zytologischen Abstriches hängt in hohem Masse von der Abstrichtechnik und dem Abstrichmaterial ab [3, 29, 30, 33, 55, 58, 61, 103, 105, 119]. Neue Methoden wie die Dünnschichtzytologie (liquid-based cytology = LBC) wurden in verschiedenen Ländern erprobt. Die Diskussion über die Vor- und Nachteile der 
Dünnschichtzytologie im Vergleich zur konventionellen Technik wird z. Zt. kontrovers geführt [12, 18, 33, 39a, 77, 89a, 90, 110]. Als Vorteil wird vor allem die bessere Beurteilbarkeit der Abstriche und die damit verbundene Reduktion der Anzahl nicht interpretierbarer Abstriche, deren Entnahme wiederholt werden muss, angeführt. Die Gegner der LBC führen allerdings ins Feld, dass mit einer korrekten Abstrichentnahme mit der konventionellen Technik gleiche Resultate erzielt werden können. Ein Vorteil der LBC könnte sein, dass bei Bedarf (siehe unter ASC-US) aus dem entnommenen Material eine HPV-Typisierung durchgeführt werden kann. Eine kürzlich publizierte Analyse sämtlicher Daten kommt zum Schluss, dass die marginalen Vorteile der Dünnschichtzytologie die höheren Kosten nicht rechtfertigen [111]. Das Eidgenössische Departement des Innern hat Ende 2002 für die Schweiz festgelegt, dass die Dünnschichtzytologie keine Pflichtleistung der Krankenkassen darstellt. Bis Ende 2004 ist aber diesbezüglich mit einer neuen Beurteilung zu rechnen [41].

Andere Methoden wie die Zervikographie, die Spekuloskopie und die Kontakthysteroskopie nach Hamou haben bisher keine wesentliche Bedeutung erlangt [7, 30, 36, 108, 124, 129].

Es kann heute als gesichert gelten, dass eine persistierende Infektion mit humanen Papillomaviren (HPV) eine Voraussetzung für die Entwicklung eines Zervixkarzinomes ist. So konnte in 99,7\% von 924 invasiven Zervixkarzinomen mittels PCR HPV-DNA nachgewiesen werden [128]. In zervikalen intraepithelialen Neoplasien Grad III (CIN III, high-grade SIL), welche als Vorstufen des invasiven Karzinoms gelten, fand sich in allen 410 untersuchten Proben molekularbiologisch HPV [15]. Auch in allen Adenocarcinoma in situ der Zervix fanden sich onkogene HPVTypen [140]. Bisher wurden über 100 verschiedene HPV-Typen identifiziert und etwa 40 können zu anogenitalen Infektionen führen. 18 verschiedene HPV-Typen sind mit invasiven Zervixkarzinomen assoziiert und werden als onkogene HPV-Typen bezeichnet. Die häufigsten in Zervixkarzinomen nachweisbaren HPV sind Typ 16 und 18 [85].

Es wird geschätzt, dass sich $80 \%$ aller Frauen und Männer während ihres Lebens mit genitalen HPV infizieren. Die Infektion ist am häufigsten in den Jahren nach Aufnahme sexueller Aktivität (Prävalenz zwischen 21 und 30 Jahren: 23,6\%), bei Frauen zwischen 30 und 34 Jahren ist die Prävalenz jedoch immer noch $14,5 \%$ und $3,8 \%$ in der Altersgruppe von 55 bis 60 Jahren $[27,132]$. Es wird geschätzt, dass bei etwa $10 \%$ der mit onkogenen HPV-Typen infizierten
Frauen der Infekt über 5 Jahre persistiert und dass diese Frauen ein Risiko von etwa 50\% haben, eine Krebsvorstufe zu entwickeln [136]. Das Risiko der malignen Transformation hängt jedoch nicht nur vom Virustyp und der Infektionsdauer $\mathrm{ab}$, sondern auch von der Anzahl der Viren im Körper. Aufgrund der hohen Prävalenz onkogener HPV-Infektionen ist einleuchtend, dass der HPV-Test nicht als generelles Screening eingesetzt werden kann. Somit bleibt er speziellen Fragestellungen vorbehalten.

Wenn der HPV-Test als Screening-Methode eingesetzt werden soll, dann in Patientinnengruppen mit einer niedrigeren Prävalenz der transienten HPV-Infektion [27, 94]. Deshalb kam die Konsensuskonferenz des amerikanischen National Institute of Health, der American Society of Colposcopy and Cervical Pathology (ASCCP) und der American Cancer Society zum Schluss, dass der HPV-Test bei über 30jährigen Frauen zusammen mit der Zytologie als ScreeningMethode eingesetzt werden könne. Wenn beide Screening-Tests negativ ausfallen, soll der nächste Screening-Test erst wieder in 3 Jahren durchgeführt werden [137]. Die Empfehlung, das nächste Screening erst in 3 Jahren durchzuführen, basiert auf einer grossen Kohortenstudie an 20810 Frauen mit mittlerer Nachkontrollzeit von 10 Jahren [40a, 118]. Frauen mit suspekter oder positiver Zytologie und negativem HPVTest hatten ein sehr niedriges Risiko der Entwicklung einer CIN III oder eines invasiven Karzinoms. Insgesamt traten bei 171 Frauen CIN III oder Karzinome auf (0,8\%). Bei negativer Zytologie und negativem HPV-Test betrug dieses Risiko nur 0,16\% (95\% CI = 0,08-0,24\%) für die folgenden 45 Monate. Bei positivem HPVTest und negativer Zytologie soll keine Kolposkopie durchgeführt, jedoch die Zytologie in 6 bis 12 Monaten wiederholt werden.

Auch bei Frauen älter als 30 Jahre ist die Prävalenz von HPV jedoch noch hoch (3,8-14,5\%, je nach Altersgruppe), die Infektion vorübergehend (45\% HPV-negativ des HPV-Tests innerhalb 6-12 Monate) und der prädiktive Wert für höhergradige Neoplasien nur 11,4-12,8\% $[27,94]$. Somit werden auch bei Frauen über 30 mehr als $87 \%$ der HPV-Positiven keine höhergradige CIN haben.

Zusammenfassend kann die Implementierung eines Screening-HPV-Tests zusätzlich zur Zytologie bei älteren Frauen nur dann sinnvoll sein, wenn bei negativem Resultat als Konsequenz das Screening-Intervall verlängert wird (3-5 Jahre). Ob diese Strategie jedoch kosteneffektiv ist, hängt vom einzelnen Gesundheitssystem ab und muss somit für jedes System 
separat berechnet werden [39a, 89a]. Zudem ist die Akzeptanz eines solchen Tests in der Bevölkerung ungeklärt, insbesondere sind die Stigmatisierung der HPV-positiven Frauen und eine Überdiagnostik und -therapie zu befürchten.

Aus Langzeitbeobachtungen weiss man, dass sich Vorstufen des Zervixkarzinoms progressiv, persistent und regressiv verhalten können [21, $38,46,55,71,72,78,95,103,115]$. Je geringgradiger die Läsion ist, desto häufiger kann mit einer spontanen Regression gerechnet werden und umgekehrt. Der Schweregrad der Läsion bestimmt nebst anderen Faktoren, wie z. B. Grösse und Lokalisation, das Vorgehen.

\subsection{Ziel der Empfehlungen}

Die Empfehlungen sollen der Ärztin/dem Arzt den Stand der wissenschaftlichen Evidenz für die Vorgehensweise bei Vorliegen eines suspekten (fraglich positiven) oder positiven zytologischen Abstriches nach Papanicolaou der Cervix uteri aufzeigen mit dem Ziel, Vorstufen des Zervixkarzinoms frühzeitig zu erfassen und der Patientin, falls überhaupt nötig, eine schonende Therapie zu ermöglichen.

\subsection{Methode}

Um einen Konsens in der Schweizerischen Gesellschaft für Geburtshilfe und Gynäkologie (SGGG) zu erreichen, wurde für die vorliegende Guideline gemäss Vorgaben der Kommission Qualitätssicherung der SGGG wie folgt vorgegangen:

Grad der Evidenz (Canadian Task Force on the Periodic Health Examination) Grad I: Die Evidenz ist aufgrund randomisierter kontrollierter Studien (oder Metaanalysen) von genügendem Umfang derart, dass die Gefahr, dass sie falsch positive oder falsch negative Resultate beinhalten, gering ist.

Grad II: Die Evidenz basiert auf randomisierten kontrollierten Studien, welche jedoch zu klein sind, um ihnen Grad I zuzusprechen; sie können positive Trends, welche jedoch statistisch nicht signifikant sind, oder gar keine Trends zeigen. Sie sind mit einem hohen Risiko falsch negativer Resultate verbunden.

Grad III: Die Evidenz basiert auf nicht randomisierten Kontroll- oder Kohortenstudien, Fallserien, Fallkontrollstudien oder Querschnittstudien.

Grad IV: Die Evidenz basiert auf der Meinung angesehener Experten oder Expertengremien, wie sie in publizierten Konsenskonferenzen oder in Guidelines angegeben werden.

Grad V: Die Evidenz basiert auf der Meinung derjenigen Personen, welche diese Guidelines geschrieben oder aktualisiert haben, beruhend auf ihrer Erfahrung, ihrer Kenntnis der einschlägigen Literatur und der Diskussion mit ihren Fachkollegen.
- Die Kommission Qualitätssicherung beauftragte eine Expertengruppe unter der Leitung von Prof. S. Heinzl, Bruderholz/Basel, mit der Ausarbeitung der Guideline.

- Die Mitglieder dieser Expertengruppe trafen sich nach Publikation der Version 1.9 mehrmals, um die neuen Literaturerkenntnisse wie auch die Kommentare zur 1. Version zu diskutieren und die 2. Version abzustimmen. Eine weitere Überarbeitung ist in 2 Jahren vorgesehen.

- Die Erstellung dieser Guideline erfolgte strikte innerhalb der SGGG. Die Expertengruppe besteht aus in der freien Praxis tätigen, aus zytologisch tätigen und aus speziell in diesem Bereich, auch wissenschaftlich tätigen Gynäkologen und einem Zytopathologen. Die Expertengruppe wurde in keiner Weise gesponsert; es bestehen keinerlei Abhängigkeiten.

Die Literatursuche wurde mit Hilfe der MedlineDatenbank für den Zeitraum von 1990 bis Januar 2004 unter folgenden Stichworten durchgeführt: Zytologie, HPV-Infekt, PAP-Abstrich, Vorgehen bei zytologischem Verdachtsbefund, Dysplasie, zervikale intraepitheliale Neoplasie, squamöse intraepitheliale Läsion und Therapie bei CIN/SIL. Dazu wurde die ganze zur Verfügung stehende deutsch-, englisch- und z.T. auch französischsprachige Literatur systematisch analysiert.

Im Rahmen ihrer Sitzungen überprüfte die Kommission Qualitätssicherung die jeweiligen Vorschläge und erteilte Überarbeitungsaufträge.

Nach Verabschiedung durch die Kommission Qualitätssicherung wurde die Leitlinie dem Vorstand der SGGG zur Verabschiedung und Weiterleitung an die Guidelinekommission der Verbindung der Schweizer Ärztinnen und Ärzte FMH unterbreitet.

Die Implementierung der Leitlinien erfolgt über Publikationen in den Printmedien, Verbreitung durch Internet, Aufnahme durch die Akademie für Fortbildung der Schweizerischen Gesellschaft für Gynäkologie und Geburtshilfe (SGGG) und Einsatz in den Weiter- und Fortbildungsveranstaltungen der SGGG. Jedes Mitglied der SGGG erhält ein Exemplar zugestellt.

$\mathrm{Zu}$ den einzelnen klinisch entscheidenden Aussagen der Leitlinie wurde der Grad der wissenschaftlichen Sicherung gemäss der Klassifikation der Canadian Task Force on the Periodic Health Examination (Kasten) beurteilt und angegeben. Damit lässt sich aussagen, ob die einzelnen Entscheidungen hauptsächlich auf Evidenz oder Konsens zustande gekommen sind. 


\subsection{Definitionen}

Die Ergebnisse der Zervixzytologie werden bisher unterschiedlich wiedergegeben. In der Schweiz sind z.Zt. verschiedene Nomenklaturen in Gebrauch (Tab. 1):

- Originaleinteilung nach Papanicolaou;

- Münchner Nomenklatur I und II;

- deskriptive Beschreibung nach WHO;

- Klassifikation von Richart (CIN);

- Bethesda-Nomenklatur 2001 (SIL);

- verschiedene laborspezifische Nomenklaturen.

Eine Kommission der Schweizerischen Gesellschaft für Zytologie, der Schweizerischen Gesellschaft für Pathologie und der Schweizerischen Gesellschaft für Geburtshilfe und Gynäkologie haben nach Prüfung die Empfehlung erarbeitet, die Bethesda-Nomenklatur 2001 einzuführen. Die Bethesda-Nomenklatur, welche für die gesamte Schweiz Gültigkeit haben soll, ist einfach, klinisch orientiert und logisch aufgebaut. Die Vereinheitlichung im ganzen Land würde viele Probleme und Missverständnisse verhindern [42, 106]. Entsprechend den therapeutischen Konsequenzen, wie sie die Bethesda-Nomenklatur vorsieht, empfiehlt sich die Dreiteilung in gering- und schwergradig positive sowie zweifelhafte Befunde [55, 71, 96, 119].

Low-grade SIL (LSIL)

Eine gering- bzw. leichtgradig positive Zytologie liegt vor, wenn zytologisch im Abstrich mild, geringgradig oder leicht dysplastische Zellen nachgewiesen werden können. Je nach Nomenklatur werden diese Befunde heute noch unterschiedlich bezeichnet: PAP II w, PAP II-III, PAP III D oder leichte, milde oder geringe Dysplasie, zervikale intraepitheliale Neoplasie ${ }^{\circ}$ (CIN I) oder «low-grade squamous intraepithelial lesion» (LSIL) mit und ohne HPV-Infekt [37, 52, 68, 74, $75,116]$.

\section{High-grade SIL (HSIL)}

Werden mittelschwer (mässig) und/oder schwer (deutlich) dysplastische Zellen oder gar Tumorzellen nebst anderen Kriterien gefunden, so spricht man von einer schwergradig positiven Zytologie. Die Nomenklatur ist hier ebenso vielfältig: PAP IV, PAP IVa, PAP IV-V, PAP V, CIN II-III, High-grade SIL (HSIL) oder Verdacht auf Karzinom [51, 55, 96].

ASC

Kann sich der Zytologe bei einer vermuteten Läsion nicht festlegen, wird dies als PAP III, ASC-H (atypical squamous cell - cannot exclude high- grade SIL) oder als ASC-US (atypical squamous cells of uncertain significance) bewertet, in der Münchner Nomenklatur entsprechend PAP III.

\section{AGC, AIS}

Handelt es sich um atypische Drüsenzellen, wird AGC-NOS (atypical glandular cells - not otherwise specified) von AGC-favor neoplasia und AIS (Adenocarcinoma in situ) unterschieden. Eine Beschreibung in Worten ist ebenfalls möglich $[55,65,73,120,123]$.

\subsection{Patientinnen}

Im Rahmen der von Land zu Land unterschiedlichen Vorsorgeuntersuchungsprogramme werden aufgrund theoretischer oder gesundheitspolitischer Überlegungen die zytologischen Abstriche in Abständen bis zu 3, mancherorts sogar bis zu 5 Jahren entnommen [17, 32, 39, 45, 63, $88,131]$. Aus epidemiologischer Sicht ist der Anteil der Frauen, die sich am Screening beteiligen, viel wichtiger einzustufen als der Abstand zwischen den einzelnen Untersuchungen [51, 63, 72, 114, 115].

In der Schweiz sind im Krankenversicherungsgesetz (KVG) folgende Richtlinien festgelegt worden:

\section{Zielpopulation}

Frauen ab 18 Jahren (oder Beginn der sexuellen Aktivität) bis zu 69 Jahren.

\section{Häufigkeit der Leistung}

Alle 3 Jahre nach 2 vorausgegangenen unverdächtigen jährlichen Abstrichen.

\section{Bemerkung}

Eine erhöhte Untersuchungsfrequenz kann bei Vorliegen von Risikofaktoren ins Auge gefasst werden.

Als Risikofaktoren für die Entwicklung einer Präkanzerose oder eines Karzinoms an der Zervix gelten [21, 31, 47, 48, 54, 70, 80]:

- frühe erste sexuelle Beziehung;

- erhöhte Anzahl von Sexualpartnern bzw. -partnerinnen;

- Partner mit seinerseits mehreren Sexualpartnern;

- Status nach venerischen Infektionen;

- Status nach HPV-Infektion;

- Nikotinabusus;

- niederer Sozialstatus;

- Langzeiteinnahme oraler Kontrazeptiva;

- Mangel an Vitaminen A, C, B, Karotin und Folsäure;

- Immunsuppression; 
- Status nach behandelter CIN/SIL;

- pathologischer Zervixabstrich in der Anamnese.

Frauen nach einer Hysterektomie gelten als sogenannte Low-risk-Fälle [2, 10].

\subsection{Häufigkeit}

Die Häufigkeit einer suspekten oder positiven Zervixzytologie richtet sich nach dem untersuchten Kollektiv. Es gibt geographische Unterschiede in Prävalenz wie auch Inzidenz. Die Neuentdeckungsrate einer zweifelhaften oder positiven Zytologie schwankt je nach Gegend und Untersuchungskollektiv zwischen 1 und 2\% und 5 und $6 \%$. Klar schwergradig positive Abstriche finden sich in etwa 1\% aller Fälle [19, 20, $39,58,82,84,89,91,127]$.

\section{Zusammenfassung der Empfehlungen}

- Die Entnahme eines Zellabstriches von der Portio bzw. Cervix uteri ist z.Zt. die beste Methode, um Vor- und Frühstadien des Zervixkarzinoms zu erfassen. Idealerweise wird der Abstrich jährlich entnommen. Das Krankenversicherungsgesetz (KVG) sieht jedoch eine Abstrichfrequenz nur alle 3 Jahre nach 2 unverdächtigen jährlichen Kontrollen vor. Eine erhöhte Untersuchungsfrequenz (jährlich) ist nur bei Vorliegen von Risikofaktoren vorgesehen.

- In der Schweiz muss die Routineabstrichentnahme vom 18. oder früher, wenn die Aufnahme der sexuellen Aktivität vor dem 18. Lebensjahr erfolgte, bis zum 69. Lebensjahr von den Krankenkassen vergütet werden.

- Frauen nach Hysterektomie aus benignem Grund gelten als Low-risk-Fälle. Deshalb ist hier der Abstrich der Vagina nur alle 3 Jahre indiziert.

- Die besten Ergebnisse zur Früherkennung einer Zervixläsion erreicht man, wenn der zytologische Abstrich mit der Kolposkopie kombiniert wird.

- Da in der Schweiz verschiedene Nomenklaturen im Gebrauch sind, ist dringend zu raten, zur Vermeidung von Missverständnissen eine genaue Absprache mit dem zytologischen Labor über die Bezeichnung der entsprechenden Befunde vorzunehmen. Die Kommission empfiehlt, in Zukunft nur noch die Bethesda-Nomenklatur zu verwenden.

- Die Verarbeitung der entnommenen Zellen mittels der Dünnschichtmethode wird z.Zt. nicht als Pflichtleistung anerkannt. Aus diesem Grunde kann diese Methode nicht emp- fohlen werden. Nach heutiger Ansicht rechtfertigen die geringen Vorteile den höheren Preis nicht.

- Der Zusammenhang zwischen Präkanzerosen und Karzinom der Zervix und der HPVInfektion gilt als gesichert. Da bei fast allen Läsionen (LSIL und HSIL) HPV-DNA nachgewiesen werden kann, ist ein HPV-Nachweis nur bei unklaren Fällen angezeigt (ASC-US), aber nur wenn nicht sogleich eine Differentialkolposkopie erfolgen kann.

- Liegt ein geringgradig positiver Abstrich (low-grade SIL, leichte Dysplasie, CIN I) vor, genügen in der Regel nach entsprechender Information der Patientin regelmässige Kontrollen (individuelle Anpassung der Kontrollintervalle möglich). Persistiert der Befund längere Zeit oder kommt es zu einer Progression, sind eine genaue Abklärung und, je nach Ergebnis, eine adäquate Therapie (Abb. 1) angezeigt. Bei leichten Veränderungen sind unter gewissen Vorbedingungen (Läsion nicht zu gross, auf Ektozervix beschränkt, CIN I/II, konklusive Abklärung [= Übereinstimmung von Zytologie, Kolposkopie und Histologie]) ambulant durchführbare, lokal destruierende Methoden möglich.

- Kann sich der Zytologe bei einem zweifelhaften Befund nicht festlegen (ASC-H, ASC-US, AGC-NOS, AGC-favor neoplasia, PAP III), ist ebenfalls eine weitere Abklärung angezeigt, da sich häufig doch dysplastische Vorgänge dahinter verbergen. Bei ASC-US kann ein HPV-Test auf onkogene HPV-Typen indiziert sein, wenn eine kolposkopische Abklärung nicht zur Verfügung steht. Bei auf onkogene HPV positivem Test muss dann eine Kolposkopie erfolgen, bei negativem Test die Kontrolle in 12 Monaten. In der Schweiz ist es jedoch immer möglich, eine kompetente kolposkopische Abklärung zu erhalten.

- Zeigt der Abstrich eine schwergradige Dysplasie, muss in jedem Fall weiter abgeklärt werden. Die Abklärung umfasst eine unter Umständen nochmalige Abstrichentnahme, eine sogenannte erweiterte Kolposkopie (Nativbetrachtung sowie Essigsäure- und Jodprobe) und eine histologische Abklärung (Biopsie, endozervikale Curettage und/oder Konisation).

- Kann ein invasives Karzinom nicht mit Sicherheit ausgeschlossen oder bestätigt werden oder sind die Abklärungsergebnisse nicht konklusiv, ist in jedem Falle eine diagnostische Konisation, sei es mit dem Messer, Laser oder der elektrischen Schlinge (LOOP), angebracht. 
- Die Therapie richtet sich nach dem Ergebnis der Abklärung und ist von weiteren verschiedenen Faktoren abhängig.

- Zur Therapie stehen verschiedenste Methoden zur Verfügung, die zum Teil ambulant und in Lokalanästhesie durchgeführt werden können.

\section{Abklärung und weiteres Vorgehen bei Vorliegen eines suspekten oder positiven Zervixabstrichs}

\subsection{Abklärung}

Die Abklärung ist an Vorbedingungen gebunden: Einerseits muss das erforderliche Instrumentarium vorhanden sein, und andererseits hat sich der Untersucher über eine entsprechende fachliche Qualifikation (Facharzt oder Arzt mit Zusatzausbildung) auszuweisen [43, 64, 71, 80].

Der Abklärungsgang umfasst die folgenden Schritte:

- Inspektion und obligate Reinigung der Portio eventuell mit physiologischer Kochsalzlösung zum Entfernen von Schleim und Detritus vor der Abstrichentnahme;

- Kolposkopie: nativ und eventuell mit Grünfilter;

- gezielte Abstrichentnahme ektozervikal mit adäquatem Abnahmegerät am besten unter kolposkopischer Kontrolle (Watteträger obsolet!);

- endozervikale Abstrichentnahme z.B. mit einem Holzspatel, Szalay-Spatel, Cyto-Brush oder mit Bürste (Cervex);

- die ektozervikale und endozervikale Entnahme kann auch in einem Arbeitsgang kombiniert werden, z.B. mit dem SzalaySpatel oder dem Cervexbrush;

- erweiterte Kolposkopie mit 3\%iger Essigsäure- und Jodprobe (Lugol'sche Lösung);

- kolposkopisch gezielte Biopsie am Punctum maximum der Läsion mit Biopsiezange;

- endozervikale Gewebeentnahme mit konventioneller Curette (Zervixabrasio), GUSBERGCurette oder scharfem Löffel bei kolposkopischem Verdacht auf endozervikale Läsion.

\subsection{Vorgehen}

Low-grade SIL (LSIL)

Liegt lediglich der Verdacht einer gering- bzw. leichtgradigen Veränderung (Abb. 1) vor, genügt eine Wiederholung des Abstriches nach 6 Monaten, da bei dieser Gruppe einerseits relativ viele falsch positive Abstriche und andererseits häufig Regressionen (bis zu 70\%) vorkommen. Bei der Wiederholung des zytologischen Abstriches soll differenziert kolposkopiert werden, insbesondere zur gezielten Abstrichentnahme, wenn dies nicht schon bei der Erstuntersuchung erfolgte. Die erweiterte Kolposkopie ermöglicht bei entsprechendem Befund eine präzise Gewebsentnahme, welche nur bei einer Diskrepanz zwischen dem kolposkopischen Befund und dem zytologischen Befund zwingend gefordert wird. Allgemein ist zu bedenken, dass unnötige Abklärungen zur Verunsicherung der Patientin führen $[102,119]$.

Ein HPV-Test macht keinen Sinn, da in der ALTS-Studie [36] 83\% der Patientinnen mit LSIL einen positiven Test für onkogene HPV zeigten $[5,6]$. Zytologische und kolposkopische Kontrollen alle 6 Monate, je nach persönlicher Situation der Frau (Ängstlichkeit, Zuverlässigkeit usw.), evtl. schon nach 3 Monaten sind ausreichend. Eine Therapie ist angezeigt, wenn sich die Läsion progressiv entwickelt bzw. über 2 Jahre persistiert. Eine Therapie zu einem früheren Zeitpunkt kann unter besonderen Umständen erwogen werden, z. B. bei Karzinophobie bzw. auf Wunsch der Patientin und bei Vorliegen besonderer Risikofaktoren [17, 32, 43, 131]. Als sehr gefährdet gelten HIV-positive und immunsupprimierte Frauen!

Neuerdings wird, vor allem in den USA, das sogenannte «see and treat»-Konzept propagiert, d.h., bei Verdacht auf eine Läsion wird sofort die Therapie angeschlossen. Dies führt sehr häufig zu unnötigen Behandlungen. Zum jetzigen Zeitpunkt ist dieses Konzept in der Schweiz nicht zu empfehlen, es sollte noch ausführlich geprüft werden [32, 47, 76, 96] (Evidenz III).

\section{ASC (atypical squamous cells)}

Ein zweifelhafter zytologischer Befund (PAP III [nach Münchner Nomenklatur II], ASC-H, ASCUS) erfordert in jedem Fall eine weiterführende Abklärung (Abb. 2) [55, 62, 127]. In bis zur Hälfte der Fälle verbirgt sich dahinter eine schwerwiegende Veränderung [55, 62, 82, 83, 127].

Bei zytologischem Befund ASC-US (atypical squamous cells of undetermined significance) empfehlen einige angelsächsische Autoren, den HPV-Test zur Triage einzusetzen, wenn aufgrund der Ressourcen nicht gleich eine kolposkopische Untersuchung durchgeführt werden kann. Es wird geschätzt, dass ein Drittel der Frauen mit ASC-US in der Folge eine höhergradige Läsion (CIN II oder mehr) entwickeln werden [57]. Eine Metaanalyse bestätigt die Resultate der ALTS-Studie, aufgrund welcher bei ASC-US drei mögliche Prozedere empfohlen werden $[4,6,121]$ : erstens 
die unmittelbare Kolposkopie, zweitens die zytologische Kontrolle alle 4 bis 6 Monate, bis zwei normale Krebsabstriche vorliegen, und drittens die HPV-Testung mit Zuweisung zur Kolposkopie bei onkogenem HPV-Infekt oder zytologische Kontrolle in 12 Monaten bei negativem HPV-Test. In der Metaanalyse war in den 8 Studien, die den Hybrid-Capture-II-Test benutzen, die Sensitivität des HPV-Tests mit 94,8\% und die Spezifität mit $67,3 \%$ höher als die der Kontrollzytologie (ASC-US oder mehr, 81,8\% beziehungsweise 57,6\%). In der ALTS-Studie mit 3488 Frauen mit ASC-US betrug der positive Voraussagewert für CIN II oder mehr 20\% und der negative Voraussagewert 99\%. In der Metaanalyse betrug der positive Voraussagewert $26 \%$ und der negative Voraussagewert ebenfalls 99\%. Der positive und negative Voraussagewert der Kontrollzytologie (erneute ASC-US oder mehr nach 6 Monaten) war mit 12\% beziehungsweise 97\% niedriger. Somit kann als gesichert gelten, dass der Einsatz eines modernen HPV-Tests in der Triage von Patientinnen mit ASC-US akkurater ist als die Wiederholung der Zytologie in $6 \mathrm{Mo}-$ naten. Ein HPV-Test bei ASC-US ist aber nur dann sinnvoll, wenn aus einem negativen Testergebnis auch tatsächlich die Konsequenzen im Sinne einer Verlängerung des Kontrollintervalls gezogen werden. Aufgrund der Ausbildung der schweizerischen Frauenärztinnen/-ärzte und auch des gesundheitspolitischen Umfeldes (Tarifierung) ist es in der Schweiz immer möglich, eine adäquate kolposkopische Beurteilung durchzuführen, weswegen dieses Vorgehen in der Schweiz nicht opportun ist.

\section{Verdacht auf glanduläre Läsionen}

Die Abklärungsschritte bestehen aus einer sorgfältigen Kolposkopie und einer endozervikalen Curettage (Abb. 2). Wenn diese Abklärung keine Pathologie zeigt, muss an eine Läsion von Endometrium, Tube oder Ovar gedacht und entsprechend abgeklärt werden. In Frage kommen eine Sonographie des Uterus und der Adnexe, eine fraktionierte Curettage, eine Hysteroskopie und/ oder eine Laparoskopie.

Bei zytologischem Verdacht auf Adenocarcinoma in situ (AIS) und AGC-favor neoplasia soll nach kolposkopischem Ausschluss eines bereits vorliegenden Adenokarzinoms die Konisation und endozervikale Curettage erfolgen. Bei gleichzeitig vorliegenden Blutungsunregelmässigkeiten oder älteren Patientinnen (>35jährig) die Korpuscurettage.

Bei AGC-NOS soll ebenfalls die sofortige Differentialkolposkopie erfolgen. Falls diese unauffällig ist, müssen mehrere kurzfristige kolpo- skopische und zytologische Kontrollen erfolgen (in 3 Monaten), da glanduläre Läsionen sowohl kolposkopisch wie auch zytologisch schwierig diagnostizierbar sind.

\section{High-grade SIL (HSIL)}

Auch bei einem schwergradig positiven Zervixabstrich (Abb. 3) muss immer eine weiterführende Abklärung vorgenommen werden [17, 32, 55, 72, 103, 119, 131], die in den Händen eines Facharztes liegen soll [43, 64, 71, 80]. Die zytologische Diagnose HSIL bedeutet, dass in 70-75\% eine CIN II oder III vorliegt. Somit ist ein exspektatives Management inakzeptabel und der HPV-Test obsolet, da sich daraus keine Konsequenz ableiten lässt [134]. Die Abklärung umfasst die Wiederholung der Zytologieentnahme, die genaue kolposkopische Untersuchung (Differentialkolposkopie) und die histologische Klärung mittels gezielter Biopsie und/ oder Curettage des Zervikalkanals. Dies ist vor allem Voraussetzung, wenn eine primäre Hysterektomie in Erwägung gezogen wird. [8, 17].

Zwingende Indikationen für eine diagnostische Konisation bei HSIL sind:

- die in ihrer gesamten Ausdehnung nicht übersehbare Grenze zwischen Platten- und Zylinderepithel;

- die zytologisch oder histologisch im Zervikalkanal nachgewiesene schwere Läsion (CIN II/III);

- der zytologische und/oder kolposkopische Verdacht auf eine Invasion;

- die signifikante Diskrepanz zwischen Zytologie, Kolposkopie und Histologie;

- der zytologische Verdacht auf eine Atypie des Zylinderepithels (glanduläre Läsion: AGCfavor neoplasia, AIS);

- der Nachweis einer Mikroinvasion in der Biopsie.

Bei nachgewiesenen Veränderungen im Bereich des Zylinderepithels ist anlässlich der Konisation eine fraktionierte Curettage mit evtl. Hysteroskopie angezeigt.

Die Konisation, lediglich durchgeführt zur Abklärung einer einmaligen zweifelhaften oder auch positiven Zervixzytologie, gilt heute als «overdiagnosis and overtreatment» und sollte unterbleiben [55, 61, 71, 103, 119] (Evidenz IV).

Bestätigt die Abklärung eine CIN II/III bzw. HSIL, soll kurzfristig eine Therapie erfolgen [17, $32,55,61,71,115,119,131]$, wenn die etwaige Konisation nicht schon das therapeutische Ziel erreichte. Lediglich weiter zu überwachen ist nur während der Schwangerschaft (Abb. 4) gestattet, wobei frühestens 6 Wochen, spätestens aber 
12 nach der Geburt die genaue Abklärung und die allfällige Therapie durchzuführen sind [43, 49, 66, 96, 130, 139] (Evidenz III).

Zentrale Bedeutung haben dabei die folgenden Faktoren:

- der Schweregrad der Läsion;

- ihre Lokalisation und Ausdehnung;

- das Alter der Patientin;

- allfällige zusätzliche genitale Veränderungen;

- der Wunsch nach definitiver Kontrazeption;

- die Einstellung der Patientin zum Leiden;

- das ärztliche und apparative Know-how;

- die Möglichkeit des Follow-up (Compliance).

\section{Karzinom}

Ergibt die Abklärung ein histologisch gesichertes Karzinom (Abb. 5), wird nach entsprechender Umgebungsabklärung die stadiengerechte Therapie angeschlossen. Dabei sind verschiedene Faktoren zu beachten [44, 55, 71, 72, 103, 119]. Neben einer umfassenden Aufklärung der Patientin sind individuelle Gegebenheiten wesentlich.

\subsection{Therapeutische Möglichkeiten} bei Vorliegen einer CIN/SIL [17, 34, 43, $51,53,61,71,84,119,131]$

1. Destruktive Methoden:
a. Diathermie oder Thermokoagulation,
b. Kryochirurgie,
c. Laservaporisation;

2. Exzsionsmethoden:

a. LEEP (Loop Electrical Excision procedure) und LLETZ (Large Loop Excision of Transformation Zone),

b. Konisation mit Messer oder Laser, c. Hysterektomie;

3. Strahlentherapie (Brachytherapie).

\section{ad 1: Destruktive Methoden}

Destruktive Methoden haben den Nachteil, dass das zerstörte Gewebe nicht histologisch nachuntersucht werden kann. Deshalb sind sie nur bei gering- bzw. leichtgradigen, streng ektozervikal gelegenen Läsionen indiziert (CIN I, evtl. CIN II). Die Portio-Zervix-Grenze (Übergang Ekto- zu Endozervix) muss eingesehen werden können, und die Flächenausdehnung sollte kolposkopisch $40 \%$ der Portiooberfläche nicht überschreiten.

Eine destruktive Behandlung bei schweren Läsionen (CIN III) ist nur in ausgewählten Fällen im Rahmen einer spezialisierten Dysplasie- sprechstunde (Fachexperte) erlaubt. Idealerweise kommt heute die Laservaporisation zum Einsatz. Elektrische Methoden und die Kryochirurgie werden wegen der mangelnden Tiefensteuerung und vor allem wegen der häufigen postoperativen Nebenerscheinungen nicht mehr empfohlen, obwohl die Ergebnisse jenen der Laservaporisation und LLETZ entsprechen.

Bei allen destruktiven Methoden fehlt die Möglichkeit der histologischen Aufarbeitung des zerstörten Gewebeareals. Deshalb sollte die Indikation hiezu sehr sorgfältig und zurückhaltend gestellt werden.

\section{ad 2: Exzisionsmethoden}

Exzisionsmethoden wie LEEP und LLETZ sind bei high-grade SIL bzw. CIN II und III zu empfehlen, sofern die Läsion nicht zu gross und kolposkopisch einsehbar ist. Die Exzision soll im Gesunden erfolgen. In besonders gelagerten Fällen können auch intrazervikale Veränderungen mit einer speziell angepassten Operationstechnik behandelt werden («cowboy hat»).

Die Messerkonisation wird bei grossen Läsionen sowie auch bei endozervikalen Läsionen eingesetzt [24, 39, 43, 76, 131]. Bei allen Arten der Konisation sollte darauf geachtet werden, histologisch beurteilbare Resektatränder zu erhalten, und es sollte unbedingt eine Fragmentierung des Konisates verhindert werden.

Die Laserkonisation gehört in die Hände eines ausgewiesenen Experten in Kolposkopie und Laserchirurgie. Die Technik erfordert grosse Geschicklichkeit. Der Eingriff kann gegebenenfalls in Lokalanästhesie durchgeführt werden.

Die Messerkonisation nach Scott wird meistens in Allgemein- oder Regionalanästhesie vorgenommen. Die Form und die Grösse des ausgeschnittenen Kegels richten sich nach Ort und Grösse der Läsion. Nähte zur Neuformierung der Portio sind nur in Ausnahmefällen nötig, zumeist genügt die Koagulation des Konusbettes.

Eine primäre Hysterektomie ist bei allfälligen Zusatzindikationen wie z.B. Blutungsanomalien, Uterus myomatosus, Descensus und anderen gegeben. Vorbedingungen sind eine konklusive Vorabklärung und ein sicherer Ausschluss eines invasiven Karzinoms.

\section{ad 3: Strahlentherapie}

Die Strahlentherapie (Brachytherapie) kann heute zur Behandlung einer Präkanzerose nicht mehr empfohlen werden. 


\subsection{Nachkontrollen nach Therapie} [71, 72, 76, 103, 115, 119]

Nach destruktiver Therapie sollte engmaschig, nach 3, 6 und 12 Monaten, nachkontrolliert werden. Verlaufen alle Kontrollen negativ, so kann die Frau wieder ins übliche Vorsorgeprogramm aufgenommen werden.

Nach Exzisionstherapie sind bei im Gesunden entfernten Läsionen Kontrollen nach 3 bis 6 Monaten, danach jährlich indiziert. Bei nicht oder nicht sicher im Gesunden entfernten Läsionen empfiehlt sich das Vorgehen wie bei nach destruktiver Therapie. Das weitere therapeutische Vorgehen richtet sich unter anderem auch danach, ob die Läsion intrazervikal oder ektozervikal nicht oder fraglich nicht im Gesunden entfernt wurde.

Obwohl randomisierte Studien fehlen, weisen prospektive Observationsstudien darauf hin, dass der HPV-Test nach erfolgter Konisation sehr sensitiv ist für residuelle oder rezidivierende CIN $[9,48,141]$. Nach Konisation wegen höhergradiger CIN werden Rezidivraten um 5\% (0,35-15\%) beobachtet $[1,9,46,48,81,100$, 141]. Bei mit CIN befallenen Konisaträndern ist die Rezidivrate mit 13-22\% höher [31, 100]. Die kumulative Inzidenz eines invasiven Zervixkarzinoms nach Konisation wegen CIN III liegt nach 10 Jahren bei 1\% [10]. Der negative Voraussagewert des HPV-Tests nach CIN-Therapie wird zwischen 92 und 100\% angegeben, was auch für

Der Präsident der Arbeitsgruppe

Der Präsident der Kommission Qualitätssicherung SGGG

Der Präsident der SGGG
Frauen mit befallenen Resektionsrändern gilt [9, $10,22,48,50,59,67,86,141]$. Der positive Voraussagewert des HPV-Tests sechs Monate nach Konisation ist höher als in der Screening-Situation und beträgt $24 \%$ [141].

Aufgrund des hohen negativen Voraussagewertes könnte ein negativer HPV-Test nach Konisation zur Folge haben, dass weniger engmaschige Nachkontrollen nötig sind. Der klinische Nutzen und die Kosteneffizienz des HPVTests sind jedoch wiederum abhängig davon, wie solche Nachkontrollen in der Praxis organisiert sind. Bei Konisation mit freien Resektionsrändern und negativer endozervikaler Curettage empfehlen wir eine kolposkopische und zytologische Kontrolle nach 6 und 12 Monaten und dann wieder jährlich. Mit diesem Nachkontrollschema macht es keinen Sinn, zusätzlich einen HPV-Test durchzuführen. In Gesundheitssystemen mit erschwertem Zugang zur Kolposkopie kann alternativ 6 Monate nach Konisation ein HPV-Test durchgeführt werden, um bei negativem Resultat auf jährliche zytologische Kontrollen überzugehen [135, 143,].

Auch nach Hysterektomien aufgrund einer Zervixpräkanzerose ist wegen der manchmal multizentrischen Entstehung [8], auch bei im Gesunden entfernten Läsionen, weiterhin eine jährliche zytologische Kontrolle des Scheidenblindsackes erforderlich.

Prof. Dr. S. Heinzl, Bruderholz / Basel

Prof. Dr. U. Haller, Zürich

Dr. L. Bronz, Bellinzona 


\section{Anhang}

Tabelle 1

Verschiedene Nomenklaturen.

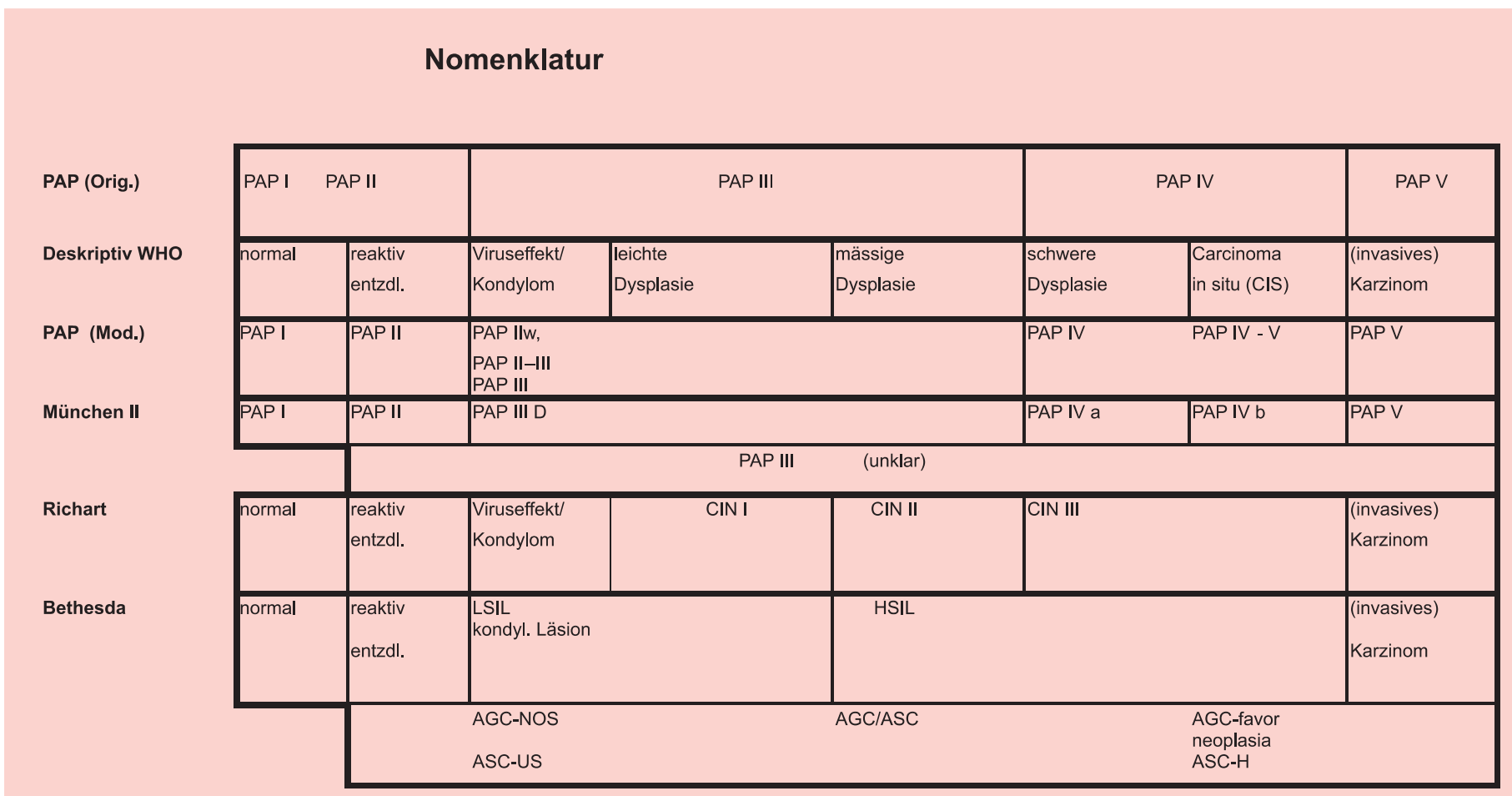

\section{Abbildung 1}

Vorgehen bei zytologischem Verdacht auf low-grade SIL.

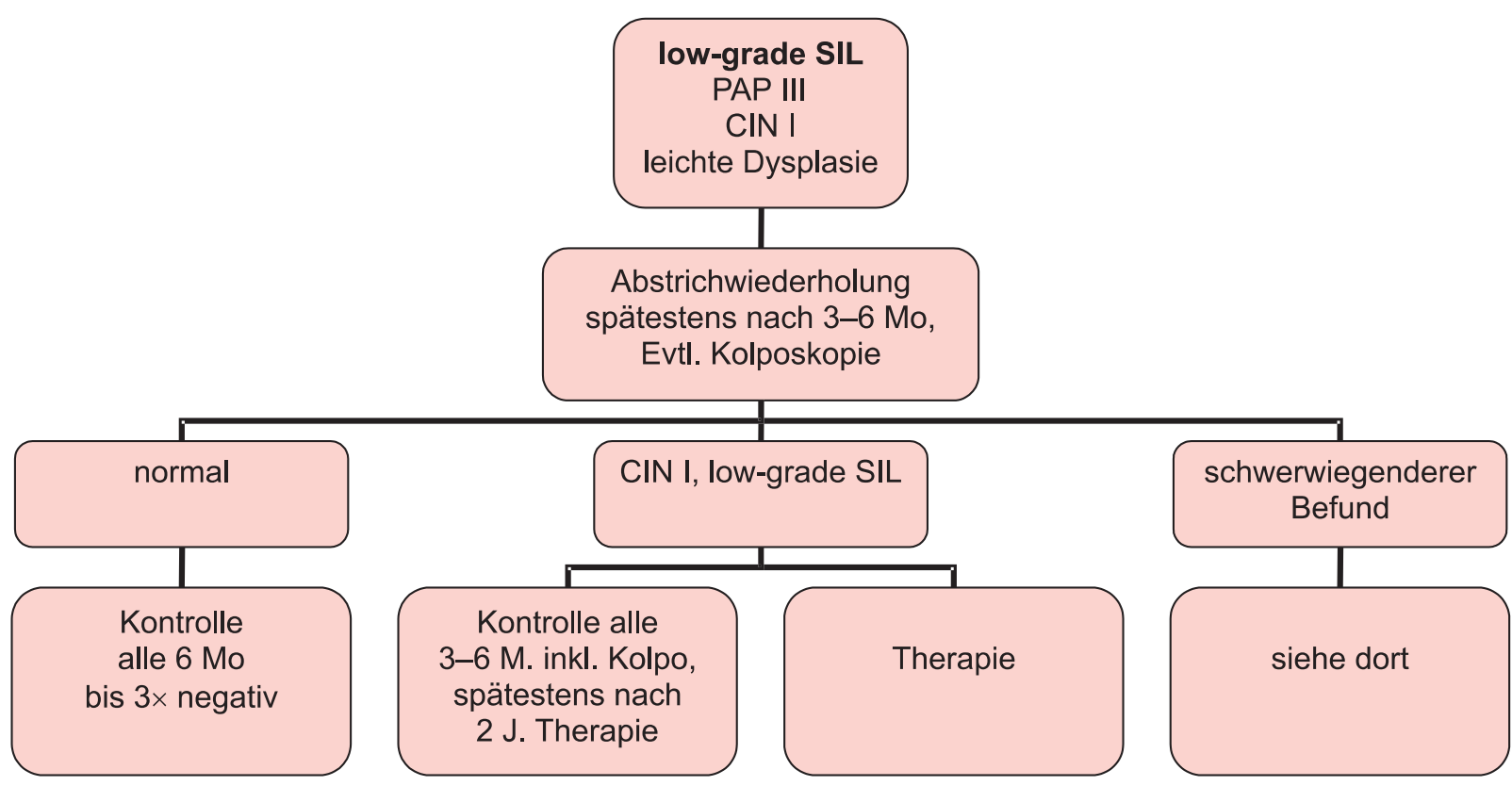


Abbildung 2

Vorgehen bei zytologischem Verdacht auf ASC und AGC.

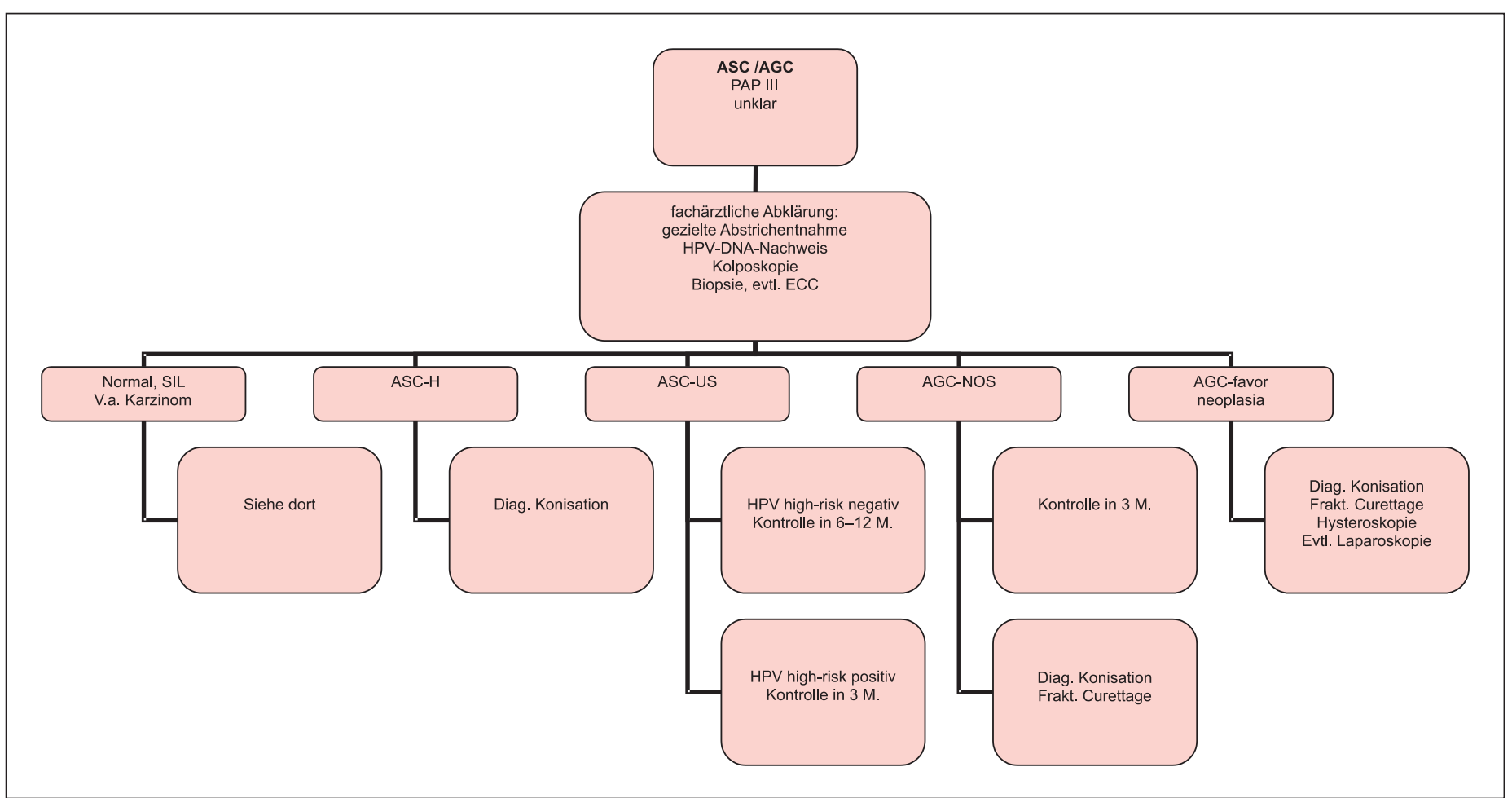

Abbildung 3

Vorgehen bei zytologischem Verdacht auf high-grade SIL.

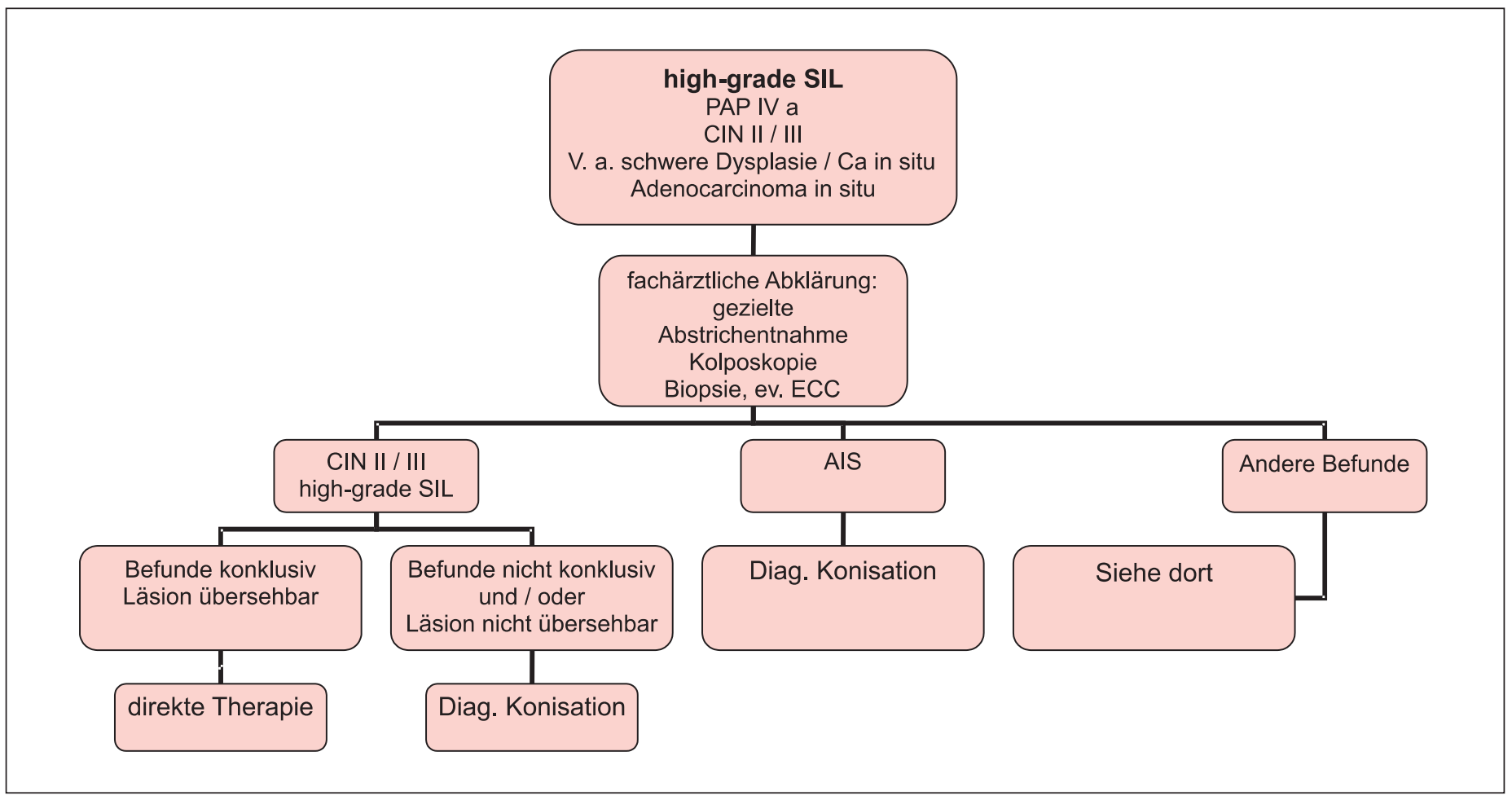


Abbildung 4

Vorgehen bei positiver oder zweifelhafter Zytologie in der Schwangerschaft.

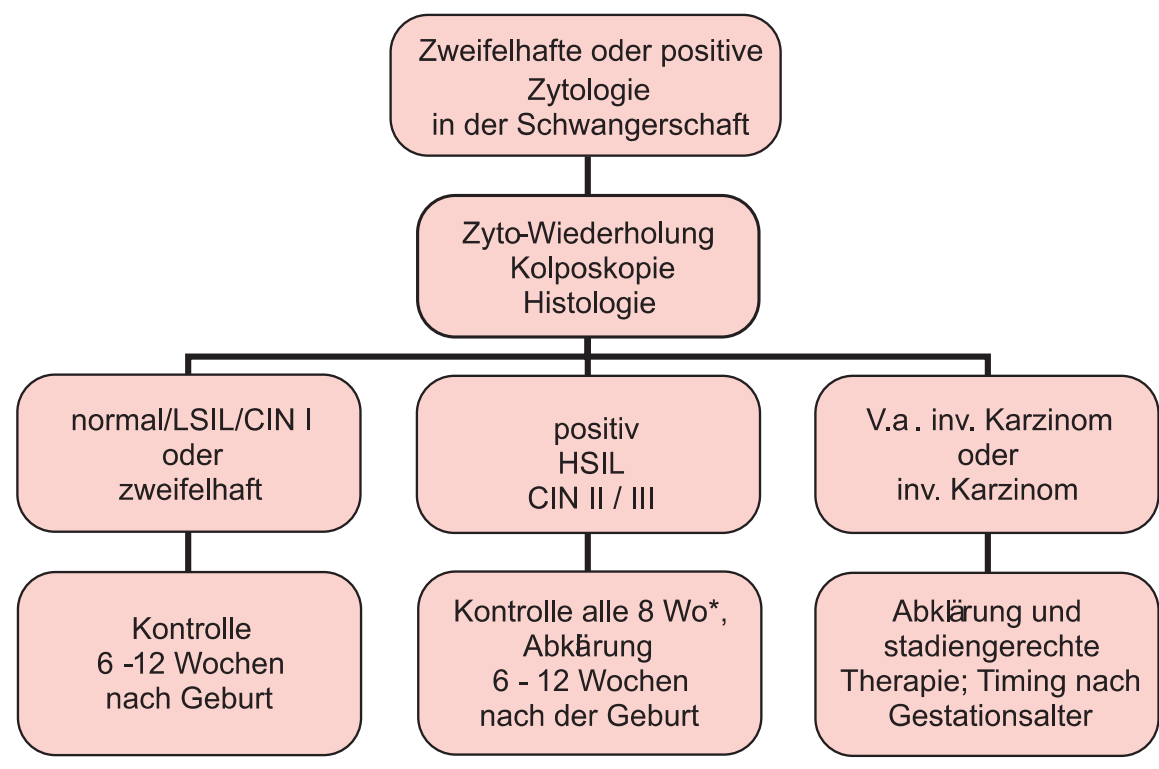

* Andere Abstände nach Rücksprache mit dem Zytologen

Abbildung 5

Vorgehen bei zytologischem Verdacht auf Karzinom.

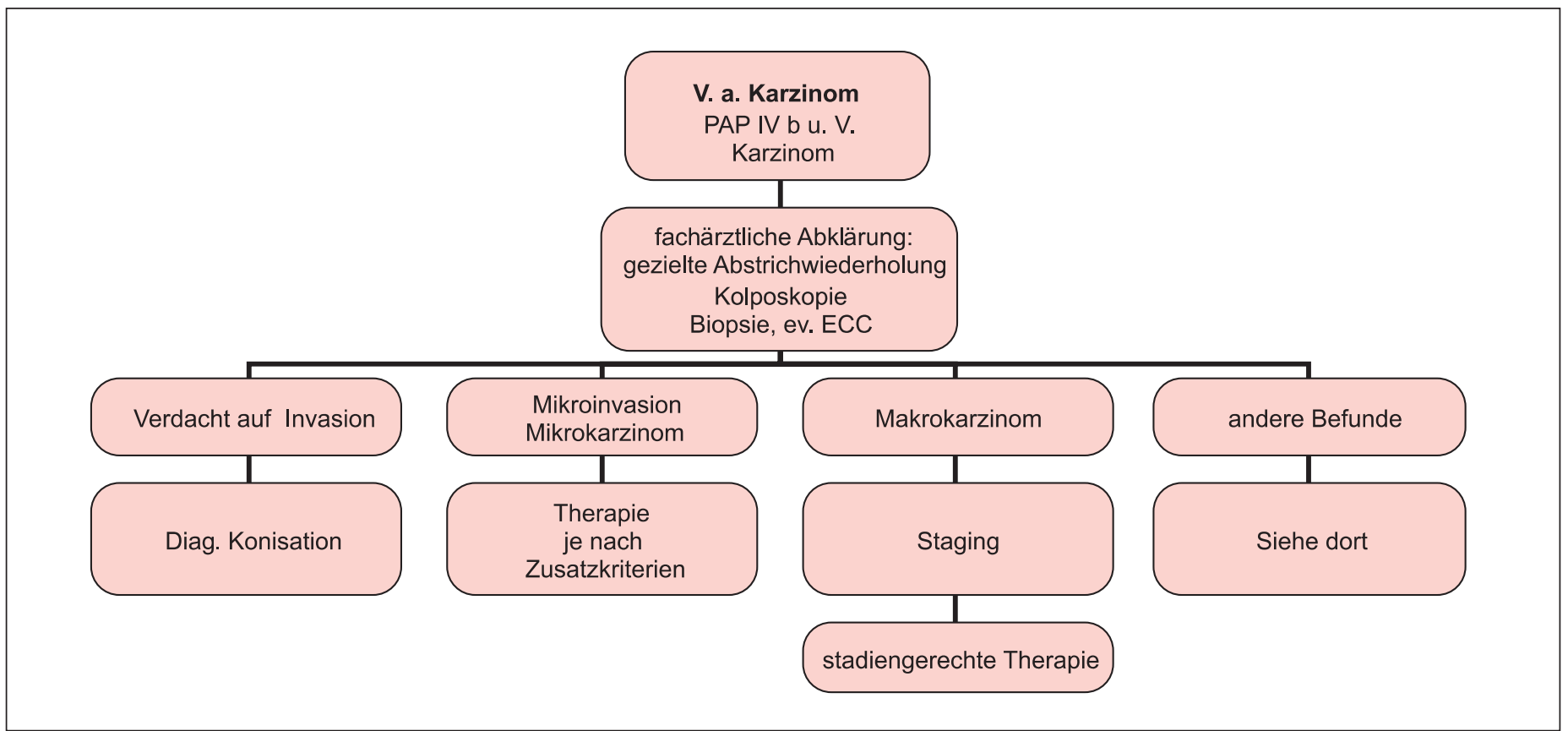




\section{Literaturverzeichnis}

1 Alvarez RD, Helm CW, Edwards RP, Naumann RW, Partridge EE, Shingleton HM, et al. Prospective randomized trial of LLETZ versus laser ablation in patients with cervical intraepithelial neoplasia. Gynecol Oncol 1994;52:175-9.

2 American College of Obstetricians and Gynecologists. Routine cancer screening. ACOG committee opinion no. 247. Washington, DC: American College of Obstetricians and Gynecologists; 2000.

3 Andrae B, Smith P. Clinical impact of quality assurance in an organized cervical screening program. Acta Obstet Gynecol Scand 1999; 78:429-35.

4 Arbyn M, Buntinx F, Van Ranst M, Paraskevaidis E, Martin-Hirsch P, Dillner J. Virologic versus cytologic triage of women with equivocal Pap smears: a meta-analysis of the accuracy to detect high-grade intraepithelial neoplasia. J Natl Cancer Inst. 2004;96(4):280-93.

5 ASCUS-LSIL Triage Study (ALTS) Group. Results of a randomized trial on the management of cytology interpretations of atypical squamous cells of undetermined significance. Am J Obstet Gynecol 2003;188:1383-92.

6 ASCUS-LSIL Traige Study (ALTS) Group. A randomized trial on the management of low-grade squamous intraepithelial lesion cytology interpretations. Am J Obstet Gynecol 2003; 188:1393-400.

7 Autier P, Coibion M, de Sutter P, et al. Cytology alone versus cytology and cervicography for cervical cancer screening: a randomized study. Obstet Gynecol 1999;93:353-8.

8 Baldauf J-J, et al. An analysis of the factors involved in the diagnostic accuracy of colposcopically directed biopsy. Acta Obstet Gynecol Scand 1997;76:468-73.

9 Bar-Am A, Gamzu R, Levin I, Fainaru O, Niv J, Almog B. Follow-up by combined cytology and human papillomavirus testing for patients postcone biopsy: results of a long-term follow-up. Gynecol Oncol 2003;91:149-53.

10 Bekkers RL, Melchers WJ, Bakkers JM, Hanselaar AG, Quint WG, Boonstra H, Massuger LF. The role of genotype-specific human papillomavirus detection in diagnosing residual cervical intraepithelial neoplasia. Int J Cancer 2002; 102:148-51.

11 Belinson J, Qiao YL, Pretorius R, Zhang WH, Elson P, Li L, et al. Shanxi Province Cervical Cancer Screening Study: a cross-sectional comparative trial of multiple techniques to detect cervical neoplasia. Gynecol Oncol 2001; 83:439-44.

12 Bergeron C, Bishop J, Lemarie A, Cas F, Ayivi J, Huynh B, Barasso R. Accuracy of thin-layer cytology in patients undergoing cervical cone biopsy. Acta Cytol 2001;45:519-24.

13 Bertelsen B, Harveit F. The cervical smear record: the relevance to the subsequent development of cervical neoplasia. Acta Obstet Gynecol Scand 1995;74:729-33.
14 Bigrigg A, Haffenden DK, Sheehan AL, Codling BW, Read MD. Efficacy and safety of large-loop excision of the transformation zone. Lancet 1994;343:32-4.

15 Bohmer G, van den Brule AJ, Brummer O, Meijer CL, Petry KU. No confirmed case of human papillomavirus DNA-negative cervical intraepithelial neoplasia grade 3 or invasive primary cancer of the uterine cervix among 511 patients. Am J Obstet Gynecol 2003;189:118-20.

16 Bollen LJ, Tjong-A-Hung SP, van der Velden J, Mol BW, Lammes FB, ten Kate FW, et al. Human papillomavirus DNA after treatment of cervical dysplasia: low prevalence in normal cytologic smears. Cancer 1996;77:2538-43.

17 Boronow RC. Death of the Papanicolaou smear? A tale of three reasons. Am J Obstet Gynecol 1998;179:391-6.

18 Broadstock M. Effectiveness and cost effectiveness of automated and semi-automated cervical screening devices: a systematic review of the literature. New Zealand Health Technology Assessment (NZHTA); The Clearing house for Health Outcomes and Health Technology Assessment. NZHTA Report, 2000.

19 Burger RA, et al. Single-visit program for cervical cancer prevention in a high-risk population. Obstet Gynecol 1995;86:491-8.

20 Burghardt E. Kolposkopie - Spezielle Zervixpathologie. Stuttgart: Thieme; 1984.

21 American Cancer Society. Cervical cancer: prevention and risk factors. www3.cancer.org/ cancer-info. Accessed March 16, 2000.

22 Chua KL, Hjerpe A. Human papillomavirus analysis as a prognostic marker following conization of the cervix uteri. Gynecol Oncol 1997; 66:108-13.

23 Clavel C, Masure M, Bory JP, Putaud I, Mangeonjean C, Lorenzato M, et al. Human papillomavirus testing in primary screening for the detection of high-grade cervical lesions: a study of 7932 women. Br J Cancer 2001; $84: 1616-23$.

24 Consensus Statement National Institutes of Health Consensus Development Conference Statement on Cervical Cancer. Gynecol Oncol 1997;66:351-61.

25 Coste J, Cochand-Priollet B, de Cremoux P, Le Gales C, Cartier I, Molinie V, et al. (French Society of Clinical Cytology Study Group). Cross sectional study of conventional cervical smear, monolayer cytology, and human papillomavirus DNA testing for cervical cancer screening. Br Med J 2003;326:733-9.

26 Cuzick J, Beverley E, Ho L, Terry G, Sapper H, Mielzynska I, et al. HPV testing in primary screening of older women. Br J Cancer 1999; 81:554-8.

27 Cuzick J, Szarewski A, Cubie H, Hulman G, Kitchener H, Luesley D, et al. Management of women who test positive for high-risk types of human papillomavirus: the HART study. Lancet 2003;362:1871-6. 
28 Dalstein V, Riethmuller D, Pretet JL, Le Bail Carval K, Sautiere JL, Carbillet JP, et al. Persistence and load of high-risk HPV are predictors for development of high-grade cervical lesions: a longitudinal French cohort study. Int J Cancer 2003;106:396-403.

29 De May RM. Common problems in Papanicolaou smear interpretation. Arch Pathol Lab Med 1997;121:229-38.

30 De Sutter P, et al. A multicentre study comparing cervicography and cytology in the detection of cervical intraepithelial neoplasia. Brit J Obstet Gynaecol 1998;105:613-20.

31 Dobbs SP, Asmussen T, Nunns D, Hollingworth J, Brown LJ, Ireland D. Does histological incomplete excision of cervical intraepithelial neoplasia following large loop excision of transformation zone increase recurrence rates? A six year cytological follow-up. BJOG 2000;107:1298-301.

32 Duncan ID. Guidelines for Clinical Practice and Programme Management. $2^{\text {nd }}$ edition. Sheffield: NHSCSP Publication No. 8; 1997.

33 Dunton CJ. New technology in Papanicolaou smear processing. Clin Obstet Gynecol 2000; 43:410-7.

34 Eaker ED, et al. Cervical cancer screening among women with and without hysterectomies. Obstet Gynecol 1998;81:551-5.

35 Elfgren K, Kalantari M, Moberger B, Hagmar B, Dillner J. A population-based five-year follow-up study of cervical human papillomavirus infection. Am J Obstet Gynecol 2000;183:561-7.

36 Etherington IJ, et al. Video colpography: a new technique for secondary cervical screening. Br J Obstet Gynaecol 1997;104:150-3.

37 Fletcher A. Dealing with the report of a mild dyskaryotic smear. Br J Obstet Gynaecol 1995; 102:517-9.

38 Franco E, Monsonego J. New developments in cervical cancer screening and prevention. Oxford: Blackwell Science; 1997.

39 Gitsch G, Kainz C. Diagnose und Therapie von zervikalen intraepithelialen Neoplasien. Speculum 1996;2:11-7.

39a Goldie SJ, Kim JJ, Wright TC. Cost-effectiveness of human papillomavirus DNA testing for cervical screening in women aged 30 years or more. Obstet Gynecol 2004;103:619-31.

40 Gunasekera PC, Phipps JH, Lewis BV. Large loop excision of the transformation zone (LLETZ) compared to carbon dioxide laser in the treatment of CIN: a superior mode of treatment. Br J Obstet Gynaecol 1990;97:995-8.

41 Gurtner P. Persönliche Mitteilung. 28. Februar 2004.

42 Hartenbach EM, Schink JC. What to do about pap smears: the Bethesda system. J Gynecol Tech 1999;5:7-10.

43 Heinrich J. Leitlinien der AG Zervixpathologie und Kolposkopie, Sektion der DGGG: Intraepitheliale Neoplasien und frühinvasive Karzinome des unteren Genitaltraktes der Frau (Cervix uteri, Vulva Vagina). Zentralbl Gynäkol 1998;120:200-2.
44 Herbst AL, et al. Pathogenesis, detection and management of cervical neoplasia: a multidisciplinary perspective. Am J Obst Gynecol 1996; 175 (suppl part 2):4.

45 Hillemanns P, et al. Epidemiologie und Diagnostik der zervikalen intraepithelialen Neoplasie Ist das derzeitige Konzept von Screening und Diagnostik noch aktuell? Gynäk Geburtsh Rundschau 1997;37:179-90.

46 Holowaty P, Miller A, Rohan T, et al. Natural history of dysplasia of the uterine cervix. J Natl Can Inst 1999;91:252-8.

47 Holzschneider C, Ghosh C, Montz F. See and treat in the management of high-grade squamous intraepithelial lesions of the cervix: a resource utilization analysis. Obstet Gynecol 1999;94:377-85.

48 Houfflin Debarge V, Collinet P, Vinatier D, Ego A, Dewilde A, Boman F, Leroy JL. Value of human papillomavirus testing after conization by loop electrosurgical excision for high-grade squamous intraepithelial lesions. Gynecol Oncol 2003;90:587-92.

49 Jain AG, et al. Management of low-grade squamous intraepithelial lesions during pregnancy. Am J Obstet Gynecol 1997;177:298-302.

50 Jain S, Tseng CJ, Horng SG, Soong YK, Pao CC. Negative predictive value of human papillomavirus test following conization of the cervix uteri. Gynecol Oncol 2001;82:177-80.

51 Jones III. HW. Cervical intraepithel neoplasia. Clinical Obstet Gynecol 1995;9:1.

52 Jones $\mathrm{MH}$. The management of the mildly dyskaryotic smear. Brit J Obstet Gynaecol 1994; 101:474-6.

53 Jones HW. Clinical treatment of women with atypical squamous cells of undetermined significance or atypical glandular cells of undetermined significance cervical cytology. Clinical Obstet Gynecol 2000;43:381-93.

54 Kaufman RH, et al. Analysis of atypical squamous (glandular) cells of undetermined significance smears by neural network - directed review. Obstet Gynecol 1998;91:556-60.

55 Kinney WK, et al. Where's the high-grade cervical neoplasia? The importance of minimally abnormal Papanicolaou diagnoses. Obstet Gynecol 1998;91:973-6.

56 Kjaer SK, van den Brule AJ, Paull G, Svare EI Sherman ME, Thomsen BL, et al. Type specific persistence of high-risk human papillomavirus (HPV) as indicator of high-grade cervical squamous intraepithelial lesions in young women: population based prospective follow-up study. Br Med J 2002;325:572-8.

57 Kinney WK, Manos MM, Hurley LB, Ransley JE. Where's the high-grade cervical neoplasia? The importance of minimally abnormal Papanicolaou diagnoses. Obstet Gynecol 1998;91:973-6.

58 Koss Leopold G. Reducing the error rate in Papanicolaou smears. The Female Patient 1994; 19:2-6. 
59 Krane JF, Lee KR, Sun D, Yuan L, Crum CP. Atypical glandular cells of undetermined significance. Outcome predictions based on human papillomavirus testing. Am J Clin Pathol 2004; 121:87-92.

60 Kulasingam SL, Hughes JP, Kiviat NB, Mao C, Weiss NS, Kuypers JM, Koutsky LA. Evaluation of human papillomavirus testing in primary screening for cervical abnormalities: comparison of sensitivity, specificity, and frequency of referral. JAMA 2002;288:1749-57.

61 Kurman RJ, et al. Interim guidelines for management of abnormal cervical cytology. JAMA 1994; 271:1866-9.

62 Lambert B, Boivin Y, Lepage Y. Atypical squamous cells of undetermined significance (ASCUS): clinical-cytological significance. Int J Gynecol Cancer 1999;9:329-32.

63 Lawson HW, et al. Cervical cancer screening among low-income women: results of a national screening program, 1991-1995. Obstet Gynecol 1998;92(5):745-52.

64 Link M, Menton M. Zur Bedeutung der kolposkopischen Untersuchung bei der Früherkennung des Zervixkarzinoms (Wissenschaftlicher Stand vom Dezember 1996 und Ergebnis einer Konsensuskonferenz zu diesem Thema am 19.12.1996 in Frankfurt/Main). Der Frauenarzt 1998;39:380.

65 Lachmann MF, Cavallo-Calvanese C. Qualification of atypical squamous cells of undetermined significance in an independent laboratory: Is it useful or significant? Am J Obstet Gynecol 1998; 179:421-9.

66 Liebermann R, Henry M, Laskin W, et al. Colposcopy in pregnancy: directed brush cytology compared with cervical biopsy. Obstet Gynecol 1999;94:198-203.

67 Lin CT, Tseng CJ, Lai CH, Hsueh S, Huang KG, Huang HJ, Chao A. Value of human papillomavirus deoxyribonucleic acid testing after conization in the prediction of residual disease in the subsequent hysterectomy specimen. Am J Obstet Gynecol 2001;184:940-5.

68 Lonky N, et al. Low-grade Papanicolaou smears and the Bethesda system: a prospective cytohistopathologic analysis. Obstet Gynecol 1995; 85:716-20.

69 Lonky N, Sadeghi M, et al. The clinical significance of the poor correlation of cervical dysplasia and cervical malignancy with referral cytologic results. Am J Obstet Gynecol 1999; 181:560-4.

70 Lorincz AT, Richart RM. Human papillomavirus DNA testing as an adjunct to cytology in cervical screening programs. Arch Pathol Lab Med 2003; 127:959-68.

71 Luesley D, Jordan J, Richart RM. Intraepithelial Neoplasia of the Lower Genital Tract. London: Churchill Livingstone; 1995.

72 Luesley DM, et al. Cancer and Precancer of the Cervix. London: Chapman \& Hall Medical; 1998.

73 Manetta A, Keefe K, Lin F, et al. Atypical glandular cells of undetermined significance in cervical cytologic findings. Am J Obstet Gynecol 1999; 180:883-8.
74 Manos M, Kinney W, Hurley L, et al. Identifying women with cervical neoplasia. JAMA 1999; 281:1605-10.

75 Meijer C, Helmerhorst T, Rozendaal L, et al. HPV typing and testing in gynaecological pathology: has the time come? Histopathology 1998; 33:83-6.

76 Matsuura Y, Kawagoe T, Toki N, Sugihara K, Kashimura M. Early cervical neoplasia confirmed by conization. Acta Cytol 1996;40:241-6.

77 Medical Services Advisory Committee (MSCA) Liquid-based cytology for cervical screening, reference 12a, Assessment report. MSAC Publications approval Na. 3174: Commonwealth of Australia 2003. Canberra: Dept. of Health and Ageing; 2003. ISBN 0-642-82177-1.

78 Melnikow J, et al. Natural history of cervical squamous intraepithelial lesions: a meta-analysis. Obstet Gynecol 1998;92:727-35.

79 Mitchell MF, et al. Gynecologic cancer prevention. Obstet Gynec Clin N Am 1996;23:2.

80 Mitchell MF, et al. Colposcopy for the diagnosis of squamous intraepithelial lesions: a metaanalysis. Obstet Gynecol 1998;91:626-31.

81 Mitchell MF, et al. A randomized clinical trial of cryotherapy, laser vaporization and loop electrosurgical excision for treatment of squamous intraepithelial lesions of the cervix. Obstet Gynecol 1998;92:737-44.

82 Monsonego J, et al. Cervical cancer control. General statements and guidelines. EUROGIN WHO International Joint Meeting (1996).

83 Monsonego J. Screening of cervical cancer for whom, why and how? - Experts' conference. EUROGIN 1994

84 Montz FJ. Management of high-grade cervical intraepithelial neoplasia and low-grade squamous intraepithelial lesion and potential complications. Clinical Obstet Gynecol 2000; 43:394-409.

85 Munoz N, Bosch FX, de Sanjose S, Herrero R, Castellsague X, Shah KV, et al. International Agency for Research on Cancer Multicenter Cervical Cancer Study Group. Epidemiologic classification of human papillomavirus types associated with cervical cancer. N Engl J Med 2003;348:518-27.

86 Nagai Y, Maehama T, Asato T, Kanazawa K. Persistence of human papillomavirus infection after therapeutic conization for CIN 3: is it an alarm for disease recurrence? Gynecol Oncol 2000; 79:294-9.

87 NG TY. Pap Smear screening and cervical cancer The Female Patient 1997;7(1):11-4.

88 Nieminen P, Kallio M, Hakama M. The effect of mass screening on incidence and mortality of squamous and adenocarcinoma of cervix uteri. Obstet Gynecol 1995;85:1017-21.

89 Nobbenhuis MA, Meijer CJ, van den Brule AJ, Rozendaal L, Voorhorst FJ, Risse EK, et al. Addition of high-risk HPV testing improves the current guidelines on follow-up after treatment for cervical intraepithelial neoplasia. Br J Cancer 2001;84:796-801. 
89a Noorani HZ, Brown A, Skidmore B, Stuart GCE. Liquid based cytology and human papillomavirus testing in cervical cancer screening. Ottawa: Canadian Coordinating Office for Health Technology Assessment; 2003. Technology report no 40. www.ccohta.ca

90 Obwegeser J, Brack S. Does liquid-based technology really improve detection of cervical neoplasia? A prospective, randomized trial comparing the ThinPrep Pap test with the conventional Pap test, including follow-up of HSIL cases. Acta Cytol 2001;45:709-14

91 Olamijulo J, Duncan ID. Is cervical cytology screening of teenagers worthwhile? Br J Obstet Gynaecol 1995;102:515-6.

92 Park A, Lee SN, Chae S, Park K, Kim J, Lee H. Comparing the accuracy of ThinPrep pap test and conventional Papanicolaou smears on the basis of histological diagnosis. A clinical study of women with cervical abnormalities. Acta Cytol 2001;45:525-31.

93 Payne N, Chillcot J, McGoogan E. Liquid-based cytology in cervical screening: a rapid and systematic review. Health Technol Assess 2000; 4(18):1-73.

94 Petry KU, Menton S, Menton M, van LoenenFrosch F, de Carvalho Gomes H, Holz B, et al. Inclusion of HPV testing in routine cervical cancer screening for women above 29 years in Germany: results for 8466 patients. Br J Cancer 2003;88:1570-7.

95 Pinto AP, Crum CP. Natural history of cervical neoplasia: defining progression and its consequence. Clinical Obstet Gynecol 2000;43:352-62.

96 Prendiville W. Diagnosis and treatment of cervical intraepithelial neoplasia. Clinical Obstet Gynecol 1995;38:3.

97 Quinn P, Babb P, Jones J, et al. Effect of screening on incidence of and mortality from cancer of cervix in England: evaluation based on routinely collected statistics. Br Med J 1999;318:904-8.

98 Ratnam S, Franco EL, Ferenczy A. Human papillomavirus testing for primary screening of cervical cancer precursors. Cancer Epidemiol Biomarkers Prev 2000;9:945-51.

99 Reich O, Pickel H, Lahousen M, Tamussino K, Winter R. Cervical intraepithelial neoplasia III: long-term outcome after cold-knife conization with clear margins. Obstet Gynecol 2001; 97:428-30.

100 Reich O, Lahousen M, Pickel H, Tamussino K, Winter R. Cervical intraepithelial neoplasia III: long-term follow-up after cold-knife conization with involved margins. Obstet Gynecol 2002; 99:193-6.

101 Richart RM, et al. Human papillomavirus, IAC task force summary. The International Academy of Cytology. Acta Cytol 1998;42:50-8.

102 Roberts RA, Blunt SM. The psychological reaction of women to a colposcopy clinic. Br J Obstet Gynaecol 1994;101:751-2.

103 Rubin SC, Hoskins WJ. Cervical cancer and preinvasive neoplasia. Philadelphia: Raven Publishers; 1996.
104 Salmeron J, Lazcano-Ponce E, Lorincz A, Hernandez M, Hernandez P, Leyva A, et al. Comparison of HPV-based assays with Papanicolaou smears for cervical cancer screening in Morelos State, Mexico. Cancers Control 2003;14:505-12.

105 Sawaya GF, Washington AE. Cervical cancer screening: which technique should be used and why? Clinical Obstet Gynecol 1999;42:922-38.

106 Schenck U, et al. Terminology. IAC task force summary. Acta Cytol 1998;42:5-15.

107 Schiffman M, Herrero R, Hildesheim A, Sherman ME, Bratti M, Wacholder S, et al. HPV DNA testing in cervical cancer screening: results from women in a high-risk province of Costa Rica. JAMA 2000;283:87-93.

108 Schneider D, Herrero R, Bratti C, et al. Cervicography screening for cervical cancer among 8460 women in a higk-risk population. Am J Obstet Gynecol 1999;180:290-8.

109 Schneider A, Hoyer H, Lotz B, Leistritza S, Kuhne-Heid R, Nindl I, et al. Screening for highgrade cervical intra-epithelial neoplasia and cancer by testing for high-risk HPV, routine cytology or colposcopy. Int J Cancer 2000;89:529-34.

110 SIAK-Expertise über neue zytologische Methoden für das Cervix-Screening zuhanden der Eidgenössischen Leistungskommission ELK gemäss Auftrag vom 21. 3. 2000 des Bundesamtes für Sozialversicherung. Bern: BSV; 20. April 2000.

111 Siebert U, Muth C, Sroczynski G, VelascoGarrido M, Gerhardus A, Gibis B. Dünnschichtpräparationen und computergestützte Untersuchungen von Zervixabstrichen - Medizinische Effektivität, gesundheitsökonomische Evaluation und systematische Entscheidungsanalyse. www. dimidi.de/de/hta/hta_berichte/hta67_Zervix_ Gesamt_030610.pdf.

112 Sigurdsson K. Cervical cancer, Pap smear and HPV testing: An update of the role of organized Pap smear screening and HPV testing. Acta Obstet Gynecol Scand 1999;78:467-77.

113 Sigurdsson K. Trends in cervical intra-epithelial neoplasia in Iceland through 1995: evaluation of targeted age groups and screening intervals. Acta Obstet Gynecol Scand 1999;78:486-92.

114 Sherlaw-Johnson C, Gallivan S, Jenkins D. Withdrawing low-risk women from cervical screening programmes: mathematical modelling study. Br Med J 1999;318:356-60.

115 Singer A, Monaghan JM. Lower genital tract precancer. Oxford: Blackwell Science; 1994.

116 Shafi MI, et al. Randomised trial of immediate versus deferred treatment strategies for the management of minor cervical cytological abnormalities. Br J Obstet Gynaecol 1997; 104:590-4.

117 Sherman ME, Kelly D. High-grade squamous intraepithelial lesions and invasive carcinoma following the report of three negative Papanicolaou smears: screening failures or rapid progression? Mod Pathol 1992;5(3):337-43.

118 Sherman ME, Lorincz AT, Scott DR, Wacholder S, Castle PE, Glass AG, et al. Baseline cytology, human papillomavirus testing, and risk for cervical neoplasia: a 10-year cohort analysis. J Natl Cancer Inst 2003;95:46-52. 
119 Shingleton HM, Orr JW. Cancer of the cervix. Philadelphia: Lippincott Company, 1995.

120 Solomon D, et al. ASCUS and AGUS criteria. IAC task force summary. Acta Cytol 1998;42:16-24.

121 Solomon D, Schiffman M, Tarone R; ALTS Study group. Comparison of three management strategies for patients with atypical squamous cells of undetermined significance: baseline results from a randomized trial. J Natl Cancer Inst. 2001; 93:293-9.

122 Soutter WP, de Barros Lopes A, Fletcher A, Monaghan JM, Duncan ID, et al. Invasive cervical cancer after conservative therapy for cervical neoplasia. Lancet 1997;349:978-80.

123 Suh-Burgmann E, et al. Atypical squamous cells of undetermined significance: management patterns at an academic medical center. Am J Obstet Gynecol 1998;178:991-5.

124 Van Niekerk WA, et al. Colposcopy, cervicography, speculoscopy and endoscopy. IAC task force summary. Acta Cytol 1998;42:33-49.

125 Trimble E, Trimble C. Cancer: Obstetrics and Gynecology. Baltimore: Lippincott Williams and Wilkins; 1999

126 van Wijngaarden WJ, et al. Screening for cervical neoplasia in Dundee and Angus: 10 years on. Br J Obstet Gynaecol 1995;102:137-42.

127 Veljovich DS, et al. Atypical glandular cells of undetermined significance: a five-year retrospective histopathologic study. Am J Obstet Gynecol 1998;179:382-90.

128 Walboomers JM, Jacobs MV, Manos MM, Bosch FX, Kummer JA, Shah KV, et al. Human papillomavirus is a necessary cause of invasive cervical cancer worldwide. J Pathol 1999; 189:12-9.

129 Wertlake PT, et al. Effectiveness of the Papanicolaou smear and speculoscopy as compared with the Papanicolaou smear alone: a communitybased clinical trial. Obstet Gynecol 1997; $90: 421-7$

130 Wildschut HIJ, et al. When to Screen in Obstetrics and Gynecology. London: W.B. Saunders; 1996.

131 Winter R, et al. Leitlinien für die operative Behandlung des Zervixkarzinoms erstellt von der Standardkommission der Österreichischen Gesellschaft für Gynäkologie und Geburtshilfe. Gynäk Geburtsh Rundschau 1997;37:227-9.
132 Woodman CB, Collins S, Winter H, Bailey A, Ellis J, Prior P, et al. Natural history of cervical human papillomavirus infection in young women: a longitudinal cohort study. Lancet 2001;357:1831-6.

133 Wright TC Jr, Denny L, Kuhn L, Pollack A, Lorincz A. HPV DNA testing of self-collected vaginal samples compared with cytologic screening to detect cervical cancer. JAMA 2000; 283:81-6.

134 Wright TC Jr, Cox JT, Massad LS, Twiggs LB, Wilkinson EJ; ASCCP-Sponsored Consensus Conference. 2001 Consensus Guidelines for the management of women with cervical cytological abnormalities. JAMA. 2002;287:2120-9.

135 Wright TC Jr, Cox JT, Massad LS, Carlson J, Twiggs LB, Wilkinson EJ. 2001 Consensus Guidelines for the Management of Women with Cervical Intraepithelial Neoplasia. Am J Obstet Gynecol 2003;189:295-304.

136 Wright TC, Schiffman M. Adding a test for human papillomavirus DNA to cervical-cancer screening. N Engl J Med 2003;348:489-90.

137 Wright TC Jr, Schiffman M, Solomon D, Cox JT, Garcia F, Goldie S, et al. Interim guidance for the use of human papillomavirus DNA testing as an adjunct to cervical cytology for screening. Obstet Gynecol 2004;103:304-9.

138 Ylitalo N, Sorensen P, Josefsson AM, Magnusson PK, Andersen PK, Ponten J, et al. Consistent high viral load of human papillomavirus 16 and risk of cervical carcinoma in situ: a nested casecontrol study. Lancet 2000;355:2194-8.

139 Yost N, Santoso J, Mcintire D, et al. Postpartum regression of antepartum cervical intraepithelial neoplasia II and III lesions. Obstet Gynecol 1999;93:359-62.

140 Zielinski GD, Snijders PJ, Rozendaal L, Daalmeijer NF, Risse EK, Voorhorst FJ, et al. The presence of high-risk HPV combined with specific p53 and p16INK4a expression patterns points to high-risk HPV as the main causative agent for adenocarcinoma in situ and adenocarcinoma of the cervix. J Pathol 2003;201:535-43.

141 Zielinski GD, Rozendaal L, Voorhorst FJ, Berkhof J, Snijders PJ, Risse EJ, et al. HPV testing can reduce the number of follow-up visits in women treated for cervical intraepithelial neoplasia grade 3. Gynecol Oncol 2003;91:67-73. 